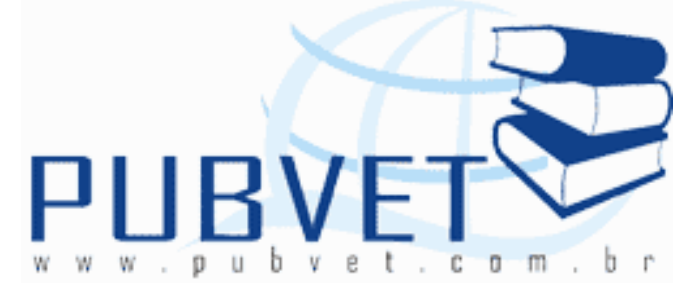

PUBVET, Publicações em Medicina Veterinária e Zootecnia.

\title{
Produção e utilização de silagens de grãos úmidos
}

Tiago Pereira Guimarães ${ }^{1}$, Kíria Karolline Gomes Moreira ${ }^{1}$, Sérgio Fernandes Ferreira ${ }^{2}$, Barbara Juliana Martins Lemos ${ }^{1}$, Flavia Martins de Souza ${ }^{1}$, Fabíola Alves Lino ${ }^{1}$

${ }^{1}$ Mestrandos do curso de Pós Graduação em Ciência Animal da Universidade Federal de Goiás - EVZ - Goiânia, Goiás, e-mail: tiagopereirarv@hotmail.com 2 Professor da Universidade Federal de Goiás - EVZ, Departamento de Produção Animal - Goiânia, Goiás.

\section{Resumo}

A ensilagem de grãos úmidos vem se destacando como uma forma eficiente de conservação de grãos de cereais para a alimentação animal, pelo menor custo e melhor valor nutritivo. A melhora na digestibilidade do amido com a utilização de grãos de alta umidade é ocasionada pela redução da interferência das matrizes proteicas do endosperma na hidrólise dessa fração, visto que estas matrizes ainda não estariam completamente formadas e solidificadas. A utilização de silagem de grão úmido constitui uma alternativa permissível na produção, pois, propicia ao animal um alimento de alto valor energético e de melhor digestibilidade, que pode ser estocado. Dispondo-se de matéria prima de qualidade e mão de obra adequada sua utilização é viável economicamente ao produtor, pois permite reduzir os custos mantendo os índices produtivos.

Palavras-chave: armazenamento, bovinos, desempenho, silagem 
GUIMARÃES, T.P. et al. Produção e utilização de silagens de grãos úmidos. PUBVET, Londrina, V. 7, N. 1, Ed. 224, Art. 1486, 2013.

\section{Production and use of moisture grain silage}

\section{Abstract}

The high moisture grain silage has emerged as an efficient storage of cereal grains for animal feed at a lower cost and better nutritional value. The improvement in the digestibility of the starch grains with the use of high humidity is caused by reducing interference of the matrix protein in the hydrolysis of the endosperm fraction, since these matrices are not already completely formed and solidified. The use of wet grain silage is an alternative permissible to produce, therefore, provides to the animal a food of high calorific value and better digestibility, which may be stored. Featuring up of raw material quality and workmanship appropriate use is economically feasible to farmer because it allows reducing costs while maintaining production rates.

Keywords: bovine, performance, silage, storage

\section{INTRODUÇÃO}

A oferta de alimentos de qualidade, sua conservação e armazenamento são fatores decisivos para alcançar valores máximos de eficiência em um sistema produtivo, sendo que, estes fatores estão diretamente relacionados com a taxa de crescimento animal. Para obtenção de eficiência biológica e econômica no processo de produção de carne, torna-se necessário oferecer aos animais condições para que apresentem satisfatório crescimento corporal, desde o nascimento até o momento do abate (IGARASI et al., 2008).

O emprego de grandes quantidades de grãos de cereais nas dietas deve-se ao fato destes serem ricos em amido, que é uma importante fonte energética. Porém, devido ao alto custo dos grãos, a dificuldade com transporte e também com o armazenamento o sistema produtivo às vezes torna-se inviável. Por isso, torna-se imprescindível a busca de meios que minimizem os custos relativos às dietas dos animais de produção.

A ensilagem de grãos úmidos vem se destacando como uma forma eficiente de conservação de grãos de cereais para a alimentação animal, pelo 
GUIMARÃES, T.P. et al. Produção e utilização de silagens de grãos úmidos. PUBVET, Londrina, V. 7, N. 1, Ed. 224, Art. 1486, 2013.

menor custo e melhor valor nutritivo (REIS et al., 2001). Foi inicialmente utilizada por criadores de suínos em 1981 na região de Castro - PR e posteriormente utilizada na alimentação de bovinos de leite e de corte. A técnica ficou restrita nesta região por aproximadamente uma década, quando iniciaram os primeiros estudos científicos no Brasil (COSTA et al., 1999).

A silagem de grãos úmidos consiste na conservação dos grãos quando estes apresentam entre 35 e $40 \%$ de umidade. Este momento é chamado de maturação fisiológica, onde cessa a transferência de nutrientes da planta para a formação dos grãos. É neste ponto que os grãos apresentam os teores máximos de amido, proteína e óleo. Da maturação fisiológica até o momento da colheita tradicional (com 12 a 13\% de umidade) há um período de 20 a 30 dias (WESCHENFELDER, 2008).

COSTA et al. (2008) afirmam que silagens de grãos úmidos de cereais podem ser consideradas como um alimento concentrado energético que complementa o volumoso, especialmente em dietas para ruminantes. $\mathrm{Na}$ alimentação de monogástricos a silagem de grãos úmidos substitui total ou parcialmente os grãos de cereais, que tradicionalmente são armazenados secos.

Segundo JOBIM et al. (2003), a colheita de grãos úmidos para a ensilagem antecipa a retirada da cultura da lavoura o que proporciona uma rotação de culturas, reduzindo as perdas quantitativas durante o processo de armazenagem e menor custo de produção em relação ao grão seco. Conforme COSTA et al. (1999), em termos econômicos, a silagem de grãos úmidos de milho pode ser até $5 \%$ mais econômica em relação aos grãos secos por eliminar as etapas de limpeza e secagem. A armazenagem dos grãos na forma de silagem também pode eliminar ou reduzir drasticamente o desenvolvimento de fungos evitando a contaminação da ração com micotoxinas (REIS et al., 2001).

Embora existam variações, principalmente em função do teor de umidade do grão e do nível de inclusão na dieta, um efeito de cerca de $10 \%$ na 
GUIMARÃES, T.P. et al. Produção e utilização de silagens de grãos úmidos. PUBVET, Londrina, V. 7, N. 1, Ed. 224, Art. 1486, 2013.

eficiência de ganho tem sido observado, principalmente devido a maior disponibilidade do amido para os animais (BERNDT et al., 2002).

BIAGGIONI et al. (2009) relataram que um aspecto interessante e que deve intensificar pesquisas visando ao aproveitamento do grão úmido como silagem refere-se à qualidade do alimento obtido.

A ensilagem do grão úmido tem como característica diferenciadora proporcionar alimento com melhor digestão enzimática do amido pelo animal. O aumento da disponibilidade de energia da dieta sem aumento do teor de concentrado pode ser obtido pelo processamento do grão, que aumenta a disponibilidade do amido para digestão (SILVA et al., 2007). O amido é potencialmente digestível, porém, sua digestão pode ser afetada por uma variedade de fatores, tais como o tipo de grão, método de processamento, método de conservação e tipo de endosperma.

Segundo NOCEK \& TAMMINGA (1991) a digestão do amido é mais eficiente no intestino delgado, porém, sua capacidade de digestão para quantidades elevadas é limitada, já no rúmen, grande parte do amido é fácil e rapidamente fermentado pelos microrganismos amilolíticos. A energia fornecida pela digestão do amido no rúmen é muito importante, visto que a síntese protéica microbiana pode ser limitada pela baixa disponibilidade de carboidratos não estruturais e pela falta de esqueletos de carbono, usado na formação de células microbianas.

A digestibilidade do amido também pode ser afetada pela sua taxa de passagem no rúmen, que varia conforme o método de conservação e a sua concentração na dieta. Sendo que a taxa de passagem do amido de milho seco moído é maior do que do milho de alta umidade (OBA \& ALLEN, 2003).

HALE (1973) constatou que a melhora na digestibilidade do amido com a utilização de grãos de alta umidade é ocasionada pela redução da interferência das matrizes protéicas do endosperma na hidrólise dessa fração, visto que estas matrizes ainda não estariam completamente formadas e solidificadas. O amido é constituído, quimicamente, por dois polissacarídeos amilose e amilopectina. A proporção destes polímeros está relacionada à taxa 
GUIMARÃES, T.P. et al. Produção e utilização de silagens de grãos úmidos. PUBVET, Londrina, V. 7, N. 1, Ed. 224, Art. 1486, 2013.

de degradação e a digestibilidade do amido, sendo que, esta última é inversamente proporcional ao teor de amilose devido a sua interação com a matriz protéica (ZINN et al., 2002).

ALMEIDA JR et al. (2008) em seus estudos concluíram que em dietas com alta porcentagem de grãos, os benefícios da ensilagem de grãos úmidos deveriam ser mais evidentes, uma vez que a ingestão diária total de amido pelo animal é maior.

Estudos mostram que, o milho na forma de silagem de grão úmido, tem o valor energético até $15 \%$ superior do que o mesmo milho na forma de grão seco e moído. Outro benefício de se utilizar o grão na forma de silagem úmida é que os grãos não são submetidos a elevadas temperaturas de secagem como ocorre, geralmente, em secadores convencionais, nos quais as temperaturas, muitas vezes, chegam a mais de $100^{\circ} \mathrm{C}$ para reduzir a umidade dos grãos até $13 \%$ e permitir seu armazenamento. As altas temperaturas reduzem, de forma significativa, a disponibilidade de nutrientes dos grãos, principalmente da proteína. Assim, uma boa silagem de grão úmido é ingrediente de alto valor nutricional que pode ter baixo custo de produção e maximizar o desempenho dos rebanhos, refletindo em maior lucratividade (PIONNER, 2012).

Dessa forma, pesquisas de viabilidade técnica, econômica, nutricional e ambiental são importantes como forma de fornecimento de subsídios para o incentivo ao aumento da utilização de silagens de grãos úmidos no Brasil.

\section{REVISÃO DE LITERATURA}

\subsection{Produção e ensilagem de grãos úmidos de cereais}

\subsubsection{Escolha do híbrido para ensilagem}

Para obter uma silagem de grão úmido de qualidade é preciso adquirir híbridos adaptados à região e se atentar para uma adequada adubação do solo. Características como adaptação regionalizada, produtividade e valor nutricional são fundamentais na escolha de um híbrido para silagem de grão 
GUIMARÃES, T.P. et al. Produção e utilização de silagens de grãos úmidos. PUBVET, Londrina, V. 7, N. 1, Ed. 224, Art. 1486, 2013.

úmido. Combinados à alta produtividade, os híbridos recomendados para silagem de grão úmido devem ter bom valor nutricional e fácil debulha com alta umidade. Elevados teores de proteína, óleo e amido são fundamentais. $\mathrm{O}$ óleo e, principalmente, o amido conferem maiores teores de energia ao grão (PIONEER, 2012).

\subsubsection{Plantio e colheita}

O plantio é feito normalmente respeitando as necessidades culturais tanto para o milho quanto para o sorgo.

O ponto de colheita do grão de milho para ensilagem deve ocorrer quando a matéria seca estiver entre 62 a 70\%. Neste ponto o grão apresenta seu melhor aproveitamento com relação ao amido presente e a digestibilidade. Com matéria seca inferior a $62 \%$ temos perda na produção do amido, com valores superiores a 70\% teremos perda na digestibilidade (KERA, 2007).

A colheita pode ser feita com antecedência de 3 ou 4 semanas em relação a colheita do grão seco, permitindo ao produtor antecipar o plantio da cultura subseqüente, melhorando a eficiência de uso da área com melhores respostas econômicas dentro do processo produtivo (FILHO, 2001). Segundo o mesmo autor, para determinar o momento correto da colheita no campo, deve-se selecionar algumas espigas de diferentes pontos do meio da lavoura, quebrando-as ao meio e observar nos grãos centrais da espiga a formação de uma camada preta na base do grão. Isso indicará se a umidade está entre $32 \mathrm{e}$ $35 \%$ - ponto de maturação fisiológica. No laboratório, a determinação da umidade é feita através de estufas ou determinador universal e serve para indicar o momento de iniciar a colheita.

\subsubsection{Processamento e armazenamento}

Logo após a colheita os grãos devem ser processados (quebrados, moídos ou laminados) e devidamente compactados. Para a alimentação de bovinos uma moagem grossa (quirera) é suficiente, ou seja, a quebra dos grãos em três a quatro pedaços (JOBIM et al., 2003). 
GUIMARÃES, T.P. et al. Produção e utilização de silagens de grãos úmidos. PUBVET, Londrina, V. 7, N. 1, Ed. 224, Art. 1486, 2013.

Para o armazenamento dos grãos úmidos pode ser utilizado qualquer tipo de silo, porém, o silo trincheira possibilita uma melhor compactação, que pode ser feita com o uso de tratores. O tamanho do silo dependerá da quantidade de alimento a ser fornecida aos animais diariamente, devendo ser retirado uma camada maior que $10 \mathrm{~cm}$ de largura de toda a parede do silo (FILHO, 2001). Quando a quantidade de silagem a ser retirada diariamente for pequena o ideal é fazer mais de um silo, com menor superfície frontal. Assim, a área de silagem exposta ao ar será menor e a espessura da fatia maior, sendo retirada diariamente toda a silagem que está em processo de deterioração (JOBIM et al., 2003). O fechamento do silo é feito com lona plástica observando uma completa vedação e expulsão do ar sobre a superfície da massa, após deve-se cobrir com terra, tijolos, telhas ou pneus.

Uma boa silagem de grão úmido deve ter no mínimo $900 \mathrm{~kg}$ de silagem por metro cúbico, sendo que o ideal é ter entre 1.100 e $1.200 \mathrm{~kg} / \mathrm{m}^{3}$ (ÍTAVO et al., 2006).

O tempo de armazenagem da silagem depende da compactação e da vedação do silo. Um silo fechado de forma adequada pode armazenar a silagem de grão úmido por vários anos. Entretanto, os produtores têm utilizado a silagem de grão úmido por um período máximo de dois anos (FILHO, 2001).

\subsection{Composição da silagem de grão úmido de milho}

A composição química da silagem de grãos úmidos de milho pode variar em função do teor de umidade no momento da ensilagem e da proporção de sabugo presente, entre outros fatores.

BIAGGIONI et al. (2009), estudaram o efeito da variação da temperatura sob a composição química - bromatológica de silagem de milho úmido que estão descritos na Tabela 1. 
GUIMARÃES, T.P. et al. Produção e utilização de silagens de grãos úmidos. PUBVET, Londrina, V. 7, N. 1, Ed. 224, Art. 1486, 2013.

TABELA 1- Resultados médios da caracterização da silagem de milho úmido (MU) e do milho seco (MS)

\begin{tabular}{|c|c|c|c|c|c|c|}
\hline Variáveis & MS & $\begin{array}{l}\text { MU } \\
5^{\circ} \mathrm{C}\end{array}$ & $\begin{array}{c}\mathrm{MU} \\
25^{\circ} \mathrm{C}\end{array}$ & $\begin{array}{c}M U \\
5 / 20^{\circ} \mathrm{C}\end{array}$ & $\begin{array}{c}\text { MU } \\
20 / 30^{\circ} \mathrm{C}\end{array}$ & $\begin{array}{c}M U \\
40^{\circ} \mathrm{C}\end{array}$ \\
\hline Umidade (\%b.u) & 13,1 & 37,5 & 35,8 & 37,3 & 32 & 37,2 \\
\hline Matéria Mineral (\%) & 1,19 & 1,18 & 0,94 & 1,1 & 1,01 & 1,35 \\
\hline Extrato Etéro (\%) & 3,9 & 5,02 & 5,03 & 5,27 & 4,34 & 4,89 \\
\hline Fibra Bruta (\%) & 2,64 & 2,98 & 3,42 & 3,44 & 2,05 & 3,03 \\
\hline Proteína Bruta (\%) & 8,54 & 9,02 & 10,26 & 10,16 & 9,05 & 8,93 \\
\hline Cálcio (\%) & 0,03 & 0,03 & 0,02 & 0,02 & 0,02 & 0,03 \\
\hline Fósforo (\%) & 0,24 & 0,25 & 0,29 & 0,27 & 0,3 & 0,3 \\
\hline Amido (\%) & 78,8 & 71,69 & 70,67 & 70,61 & 65,32 & 70,34 \\
\hline $\begin{array}{l}\text { Granulometria (\%) } \\
(\mathrm{DGM} \mu \mathrm{m})\end{array}$ & 809 & 1439 & 1168 & 1118 & 1291 & 1408 \\
\hline Compactação (kg m-3) & 803 & 1001 & 1040 & 1019 & 1029 & 1063 \\
\hline $\mathrm{pH}$ & 5,39 & 3,8 & 3,89 & 3,84 & 3,91 & 3,83 \\
\hline
\end{tabular}

Fonte: Adaptado de BIAGGIONI et al. (2009)

\subsection{Composição da silagem de grão úmido de sorgo}

Na Tabela 2 estão descritos os resultados encontrados por POMPEU (2003), que avaliou o valor nutritivo e as características fermentativas de silagens de grãos úmidos de sorgo. 
GUIMARÃES, T.P. et al. Produção e utilização de silagens de grãos úmidos. PUBVET, Londrina, V. 7, N. 1, Ed. 224, Art. 1486, 2013.

TABELA 2-Teores de matéria seca (MS), proteína bruta (PB), fibra em detergente neutro (FDN), fibra em detergente ácido (FDA), extrato etéreo $(E E)$ e potencial hidrogeniônico $(\mathrm{pH})$ de grãos úmidos de sorgo moídos e inteiros em três épocas de colheita (86, 93 e 100 dias)

\begin{tabular}{|c|c|c|c|c|c|c|}
\hline & \multicolumn{6}{|c|}{ ÉPOCAS DE COLHEITA } \\
\hline & \multicolumn{2}{|c|}{ Epoca 1} & \multicolumn{2}{|c|}{ Época 2} & \multicolumn{2}{|c|}{ Época 2} \\
\hline & MOÍDO & INTEIRO & MOÍDO & INTEIRO & MOÍDO & INTEIRO \\
\hline MS & $58,4 \mathrm{~A} \mathrm{C}$ & 56,9 B C & $63,9 \mathrm{~A} \mathrm{~b}$ & $62,0 \mathrm{~B} \mathrm{~b}$ & $72,6 \mathrm{~A}$ a & $71,1 \mathrm{~B} \mathrm{a}$ \\
\hline PB & $10,1 \mathrm{~A} \mathrm{a}$ & $10,1 \mathrm{~A} \mathrm{a}$ & $9,8 \mathrm{~A} a b$ & $10,0 \mathrm{~A} \mathrm{a}$ & $9,6 \mathrm{~A} \mathrm{~b}$ & $9,8 \mathrm{~A} \mathrm{a}$ \\
\hline FDN & 21,4 B b & $42,7 \mathrm{~A} a \mathrm{~b}$ & $21,9 \mathrm{~B} \mathrm{~b}$ & $41,1 \mathrm{~A} \mathrm{~b}$ & $35,1 \mathrm{~B} \mathrm{a}$ & $46,3 \mathrm{~A} a$ \\
\hline FDA & $6,0 \mathrm{~B} \mathrm{a}$ & $8,4 \mathrm{~A} \mathrm{a}$ & $6,5 \mathrm{~B} \mathrm{a}$ & $8,0 \mathrm{~A} \mathrm{a}$ & $6,5 \mathrm{~A} a$ & $7,3 \mathrm{~A}$ a \\
\hline $\mathrm{EE}$ & $2,9 \mathrm{~A} \mathrm{a}$ & $2,7 \mathrm{~A} \mathrm{a}$ & $3,1 \mathrm{~A} \mathrm{a}$ & $2,5 \mathrm{Aa}$ & $2,3 \mathrm{~A} \mathrm{a}$ & $2,5 \mathrm{~A} \mathrm{a}$ \\
\hline $\mathrm{pH}$ & $4,6 \mathrm{~B} \mathrm{~b}$ & $5,8 \mathrm{~A} \mathrm{~b}$ & $4,6 \mathrm{~B} \mathrm{~b}$ & $5,5 \mathrm{~A} \mathrm{C}$ & $5,9 \mathrm{~B} \mathrm{a}$ & $6,2 \mathrm{~A} \mathrm{a}$ \\
\hline
\end{tabular}

Fonte Adaptado: POMPEU (2003)

POMPEU (2003) observou que as silagens de grãos úmidos de sorgo, moídos com $41 \%$ e $33 \%$ de umidade, melhoraram o valor nutritivo elevando o teor de PB e diminuindo os teores de FDN e FDA sem comprometer o processo fermentativo. A silagem de grãos úmidos inteiros provocou aumento no teor de FDN, FDA e pH comprometendo o valor nutritivo e o processo fermentativo. Portanto a moagem dos grãos antes da ensilagem é uma prática que favorece o processo fermentativo e o valor nutritivo das silagens.

\subsection{Vantagens e desvantagens da silagem de grãos úmidos}

A utilização do grão de alta umidade na nutrição animal apresenta algumas vantagens agronômicas, como significativa redução das perdas no campo, liberação antecipada da área, redução dos custos com o processo de secagem, entre outras (BERNDT et al., 2002).

A armazenagem dos grãos na forma de silagem, em condições de manejo adequado, pode eliminar ou reduzir drasticamente o desenvolvimento 
GUIMARÃES, T.P. et al. Produção e utilização de silagens de grãos úmidos. PUBVET, Londrina, V. 7, N. 1, Ed. 224, Art. 1486, 2013.

de fungos e, em conseqüência, evitar a contaminação da ração com micotoxinas. Além disso, a tecnologia da ensilagem de grãos úmidos permite um sistema de armazenagem mais simples e barato (REIS et al., 2001).

Comparado ao sistema convencional de colheita do grão, a silagem de grão úmido tem menor custo por dispensar o transporte até o secador e o pagamento de taxas de armazenamento, além das tributações e dos descontos. Do ponto de vista nutricional, o grão úmido tem maior digestibilidade, principalmente da fração amido e, por isto, maior valor energético (PIONNER, 2012).

Algumas vantagens do uso da silagem de grãos úmidos são: antecipação na colheita em três a quatro semanas; não há transporte do produtor para a cooperativa ou fábrica de rações; não há custo de armazenamento; redução significativa das perdas de campo por condições climáticas adversas; diminuição do ataque de pássaros e de insetos, além de diminuir presença de fungos; baixos investimentos para armazenagem; menor custo de produção em relação ao grão seco e melhor desempenho animal; possui maior digestibilidade e, conseqüentemente, melhora o desempenho animal; melhora a sanidade dos animais, causando menos diarréias; tem alta concentração de energia, para balancear com alimentos protéicos. As desvantagens são: a impossibilidade de comercialização de eventuais excedentes de produção; impossibilidade de formulação de concentrado antecipadamente, ou seja, deve ser misturados aos demais ingredientes da dieta diariamente e, por ser digerida em sua maior parte e rapidamente no rúmen, pode proporcionar maior incidência de acidose, com conseqüente redução no desempenho dos animais (FILHO, 2001), (JOBIM et al., 2003).

\subsection{Desempenho de animais alimentados com silagem de grãos úmidos de milho}

Em experimento realizado com ovinos jovens terminados em confinamento, ÍTAVO et al. (2006) constataram que em dietas com proporção volumoso:concentrado 50:50, as silagens de grãos de milho e de sorgo 
GUIMARÃES, T.P. et al. Produção e utilização de silagens de grãos úmidos. PUBVET, Londrina, V. 7, N. 1, Ed. 224, Art. 1486, 2013.

úmidos proporcionaram maior ganho de peso, conversão e eficiência alimentares do que aquelas contendo grãos secos. BERNDT et al. (2002) observaram que tourinhos Santa Gertrudis alimentados com dieta incluindo milho grão úmido apresentaram maiores taxas de deposição de lipídios.

Na Tabela 3, HENRIQUE et al. (2007), apresentaram um aumento na eficiência alimentar em 9,7\% com uso da silagem de grãos de milho úmido (MU) em relação ao milho em grão seco (MS), associados à silagem de milho (SI) ou ao bagaço in natura de cana-de-açúcar (Ba), sobre o desempenho e as características da carcaça de bovinos raça Santa Gertrudes em fase de terminação.

TABELA 3- Desempenho dos animais em cada um dos tratamentos

\begin{tabular}{lccccc}
\hline \multirow{2}{*}{\multicolumn{1}{c}{ Parâmetros }} & \multicolumn{5}{c}{ Dietas } \\
\cline { 2 - 5 } & SI-MU & Si-MS & Ba-MU & Ba-MS & CV \% \\
\hline Peso da carcaça quente, kg & 282 & 288 & 289 & 286 \\
Peso final, kg & 450 & 447 & 436 & 423 & 4 \\
Ingestão de MS, kg/dia & 8,04 & 8,34 & 7,75 & 7,89 & 8,8 \\
Ingestão de MS, \% PV & 2,2 & 2,27 & 2,14 & 2,23 & 6,6 \\
Ganho de peso, kg/dia & 1,54 & 1,46 & 1,35 & 1,26 & 10,4 \\
EA, kg ganho/kg MS ingerida & 0,19 & 0,18 & 0,17 & 0,16 & 6,9 \\
\hline
\end{tabular}

Fonte: Adaptado de Henrique et al. (2007)

Os resultados obtidos por IGARASI et al. (2008), com bovinos utilizando dietas contendo silagem de sorgo úmido em substituição por silagem de milho úmido estão descritos na Tabela 4. 
GUIMARÃES, T.P. et al. Produção e utilização de silagens de grãos úmidos. PUBVET, Londrina, V. 7, N. 1, Ed. 224, Art. 1486, 2013.

TABELA 4- Características de desempenho e de carcaça de bovinos jovens alimentados com as dietas experimentais com silagem de milho úmido (TMU) e silagem de sorgo úmido (TSU)

\begin{tabular}{lccc}
\hline \multicolumn{1}{c}{ Parâmetros } & TMU & TSU & CV\% \\
\hline Peso vivo inicial, kg & 316,22 & 315,75 & \\
Peso de abate, $\mathrm{kg}$ & 514,22 & 524,31 & 3,75 \\
GPD, kg/dia & 1,5 & 1,58 & 9,63 \\
Rendimento de carcaça & 54,2 & 53,8 & 2,39 \\
EGS, mm & 5,12 & 4,58 & 22,98 \\
\hline
\end{tabular}

Fonte: Adaptado de IGARASI et al. (2008)

Os autores citaram que a substituição integral da silagem de grão úmido de milho pela silagem de grão úmido de sorgo não alterou as características qualitativas e quantitativas da carcaça de bovinos jovens em confinamento.

PANICHIA (2009) realizando trabalho com vacas holandesas em lactação observou que silagem de grãos úmidos de milho pode ser utilizada na dieta em substituição total aos grãos secos de milho, sem alterar o consumo de matéria seca, produção e composição do leite. Também se mostrou mais eficiente e proporcionou melhor aproveitamento dos nutrientes da dieta total.

PUTRINO et al. (2006), não observaram diferenças no peso final e ganho de peso médio diário (GMD) de novilhos Nelore alimentados com dietas à base de grão de milho seco ou úmido, fato também constatado por SILVEIRA et al. (2006), suplementando novilhos com silagem de grão úmido de sorgo ou grão seco de sorgo.

ALMEIDA JR. et al. (2008) não verificaram diferenças nos ganhos diários de peso de bezerros holandeses alimentados após o desaleitamento com silagem de grão úmido ou grão seco de sorgo. Esses autores salientam que, com dietas com alta percentagem de grãos, os benefícios da ensilagem de grãos úmidos deveriam ser mais evidentes, uma vez que a ingestão diária total 
GUIMARÃES, T.P. et al. Produção e utilização de silagens de grãos úmidos. PUBVET, Londrina, V. 7, N. 1, Ed. 224, Art. 1486, 2013.

de amido pelo animal é maior pela maior digestibilidade e rápida fermentação ruminal. Seria esperado um melhor desempenho de bovinos alimentados com esse tipo de grão, porém, este resultado não foi observado no presente experimento.

\section{CONSIDERAÇÕES FINAIS}

A utilização de silagem de grão úmido constitui uma alternativa permissível na produção, pois, propicia ao animal um alimento de alto valor energético e de melhor digestibilidade, que pode ser estocado.

Dispondo-se de matéria prima de qualidade e mão de obra adequada sua utilização é viável economicamente ao produtor, pois permite reduzir os custos mantendo os índices produtivos.

Há necessidade de pesquisas com silagem de grão úmido para prover respostas mais consistentes quanto à eficácia de utilização da mesma, principalmente em nível de informação aos produtores.

\section{REFERÊNCIAS}

1- ALMEIDA JR., G. A. de; COSTA, C.; CARVALHO, S. M. R. de; PERSiCHETTI JR. P.; PENICHI, A. Desempenho de bezerros holandeses alimentados após o desaleitamento com silagem de grãos úmidos ou grãs secos de milho ou sorgo. Revista Brasileira de Zootecnia. Viçosa. v. 37, n. 1, p. 148-156, 2008.

2- BERNDT, A.; HENRIQUE, W.; LANNA, D.P.D.; LEME, P. R.; ALLEONI, G. F. Milho úmido, bagaço de cana e silagem de milho em dietas de alto teor de concentrado. Composição corporal e taxas de deposição dos tecidos. Revista Brasileira de Zootecnia. Viçosa. v.31, n.5, p.2105-2112, 2002.

3- BIAGGIONI, M.A.; LOPES, A.B.C.; JASPER, S.P.; BERTO, D.A.; GONÇALVES, E.V. Qualidade da silagem de grão úmido em função da temperatura ambiente e pressão interna de armazenagem. Acta Scientiarum. Agronomy. Maringá, v. 31, n. 3, p. 377-382, 2009.

4- COSTA, C.; ARRIGONI, M.D.B.; SILVEIRA, A.C.; CHARDULO,L.A.L. Silagem de grãos úmidos. In: SIMPÓSIO SOBRE NUTRIÇÃO DE BOVINOS, 7. 1999, Piracicaba. Anais... Piracicaba: FEALQ, 1999. p.69-88.

5- COSTA, C.; SILVA, A. M. A.; MEIRELLES, P. R. L. Produção de silagem de grãos úmidos de cereais e de palma forrageira. In: I SIMPÓSIO EM SISTEMAS AGROSILVIPASTORIS NO SEMIÁRIDO (I SIMPAS), 1., 2008, Campina Grande, Palestra... Campina Grande: PPGZ/CSTR/UFCG, 2008. Disponível em: <http://www.cstr.ufcg.edu.br/acsa/palestras/Palestra_2>. Acesso em: 07/08/2012. 
6- FILHO, I. N. Silagem de grão úmido de milho. In: SEMINÁRIO NACIONAL DE DESENVOLVIMENTO DA SUINOCULTURA, 9., 2001, Gramado. Anais... Concórdia: Embrapa Suínos A Aves Disponível em: <http://www.cnpsa.embrapa.br/sgc/sgc_publicacoes/anais0104_nummer.pdf> Acesso em: 07/08/2012.

7- HALE, W.H. Influence of processing on the utilization of grain (starch) by ruminants. Journal of Animal Science, Champaign, v.37, n.4, p.1075-1081, 1973.

8- HENRIQUE, W.; FILHO, J.A.B.; LEME, P.R.; LANNA, D.P.D.; ALLEONI, G.F.; FILHO, J.L.V.C.; SAMPAIO, A.A.M. Avaliação da silagem de grãos de milho úmido com diferentes volumosos para tourinhos em terminação. Desempenho e características de carcaça. Revista Brasileira de Zootecnia. Viçosa. v.36, n.1, p.183-190, 2007.

9- IGARASI, M.S.; ARRIGONI, M.B.; HADLICH, J.C.; SILVEIRA, A.C.; MARTINS, C.L.; OLIVEIRA, H.N. Características de carcaça e parâmetros de qualidade de carne de bovinos jovens alimentados com grãos úmidos de milho ou sorgo. Revista Brasileira de Zootecnia. Viçosa. v.37, n.3, p.520-528, 2008.

10- ÍTAVO, C. C. B. F.; MORAIS, M. G.; ÍTAVO, L. C. V.; SOUZA, A. R. D. L.; OSHIRO, M. M.; BIBERG, C. C.; JOBIM, C. C.; LEMPP, B.Efeitos de diferentes fontes de concentrado sobre 0 consumo e a produção de cordeiros na fase de terminação. Revista Brasileira de Zootecnia, Viçosa. v.35, n.1, p.139-146, 2006.

11- JOBIM, C.C.; BRANCO, A.B.; SANTOS, G.T. Silagem de grãos úmidos na Alimentação de bovinos leiteiros. In: V Simpósio Goiano sobre Manejo e Nutrição de Bovinos de Corte e Leite. Goiânia - Goiás, maio 2003. p. 357-376.

12- KERA. Manual de Ensilagem Kera. Disponível em: www.kerabrasil.com.br/downloads/ manual_ensilagem.pdf. Acesso em: 13/06/2011.

13- Nocek J.E.; Tamminga; S. Site of digestion of starch in the gastrointestinal tract of dairy cows and its effect on milk yield and composition. Journal of Dairy Science, Champaign, v. 74 , p. 3598-3629, 1991.

14- OBA, M.; ALLEN, M. S. Effects of Corn Grain Conservation Method on Ruminal Digestion Kinetics for Lactating Dairy Cows at Two Dietary Starch Concentrations. Journal of Dairy Science, Champaign, v. 86, n. 1, 2003.

15- PANICHIA, A. Substituição dos grãos secos de milho pela silagem de grãos úmidos de milho para vacas da raça holandesa em lactação. 2009, 36 f. Dissertação (Mestrado em Zootecnia)- Faculdade de Medicina Veterinária e Zootecnia da Universidade Estadual Paulista, Botucatu. 2009.

16- PIONNER. Guia do Milho da Pioneer Sementes. Disponível em: <http://www.pioneersementes.com.br/upload/download/files/DownloadFile_257.pdf> Acesso em: 07/08/2012.

17- POMPEU, R.C.F.F. Valor nutritivo e características fermentativas de silagens de grãos úmidos de sorgo (Sorghum bicolor L. Moench). 2003, 60 f. Monografia (Graduação em Agronomia)- Curso de Agronomia do Centro de Ciências Agrárias da Universidade Federal do Ceará. FORTALEZA. 2003. 
18- PUTRINO, S. M.; LEME, P. R.; SILVA, S. L.; ALLEONI, G. F.; PAZZANESE, D.; LANNA, D.; GROSSKLAUS, C. Exigências líquidas de proteína e energia para ganho de pesos de novilhos Nelore alimentados com dietas contendo grão de milho úmido e gordura protegida. Revista Brasileira de Zootecnia, Viçosa, v. 35, n. 1, p. 301-308, 2006.

19- REIS, W.; JOBIM, C.C.; MACEDO, F.A.F. Desempenho de cordeiros terminados em confinamento consumindo silagens de milho de grãos com alta umidade ou grãos de milho hidratados em substituição aos grãos de milho seco da dieta. Revista Brasileira de Zootecnia, Viçosa, v.30, n.2, p.596-603, 2001.

20- SilVA, S. L.; LeME, P. R.; PUTRINo, S. M.; VALINOTE, A. C.; FilHO, J. C. M. N.; LANNA, D. P. D. Milho grão seco ou úmido com sais de cálcio de ácidos graxos para novilhos Nelore em confinamento. Revista Brasileira de Zootecnia, Viçosa, v.36, n.5, p.1426-1434, 2007.

21- SILVEIRA, M. F.; KOZLOSKI, G. V.; BRONDANI, I. L.; ALVES FILHO, D. C.;RESTLE, J.; LEITE, D. T.; METZ, P. A. M.; SILVEIRA, S. R. L. Ganho de peso vivo e fermentação ruminal em novilhos mantidos em pastagem cultivada de clima temperado e recebendo diferentes suplementos. Ciência Rural, Santa Maria, v. 36, n. 3, p. 898-903, 2006.

22- WESCHENFELDER, V.A. Alimentação de porcas lactantes com dietas contendo silagem de grãos úmidos de milho e ácidos orgânicos. 2008, 80 f. Dissertação (Mestrado em zootecnia)- Programa de Pós-Graduação em Zootecnia da Universidade Federal De Santa Maria. Santa Maria. 2008.

23- ZINN, R. A.; OWENS, F. N.; WARE, R. A. Flaking corn: processing mechanics, quality standards, and impacts on energy availability and performance of feedlot cattle. Journal of Animal Science, Champaign, v. 80, p.1145-1156, 2002. 